\title{
Reintervention with Transcatheter and Surgical Aortic Valves: A Systematic Review and Meta-Analysis
}

\author{
Kevin G. Buda1, Michael S. Megaly², Vinayak N. Bapat ${ }^{3}$, Robert Steffen³, João L. Cavalcante', \\ Santiago Garcia ${ }^{*}$
}

${ }^{1}$ Division of Internal Medicine, Hennepin Healthcare, Minneapolis, USA

${ }^{2}$ Division of Cardiology, Banner University Medical Center/University of Arizona, Phoenix, USA

${ }^{3}$ Department of Cardiac Surgery, Abbott Northwestern Hospital, Minneapolis, USA

${ }^{4}$ Minneapolis Heart Institute, Abbott Northwestern Hospital, Minneapolis, USA

Email: ^santiagogarcia@me.com

How to cite this paper: Buda, K.G., Megaly, M.S., Bapat, V.N., Steffen, R., Cavalcante, J.L. and Garcia, S. (2021) Reintervention with Transcatheter and Surgical Aortic Valves: A Systematic Review and Meta-Analysis. World Journal of Cardiovascular Diseases, 11, 249-260. https://doi.org/10.4236/wjcd.2021.115025

Received: April 9, 2021

Accepted: May 25, 2021

Published: May 28, 2021

Copyright ( 2021 by author(s) and Scientific Research Publishing Inc. This work is licensed under the Creative Commons Attribution International License (CC BY 4.0).

http://creativecommons.org/licenses/by/4.0/

(c) (i) Open Access

\begin{abstract}
Background: Despite expanding indications, data regarding the long-term durability of transcatheter heart valves (THV) are limited. Methods: We performed a systematic review and meta-analysis of all published studies with $\geq 5$ years of follow-up reporting aortic valve reintervention rates of transcatheter (TAVR) and surgical aortic valve replacement (SAVR). Randomized controlled trials $(n=4)$ and propensity-matched observational studies $(n=1)$ involving all surgical risk categories were included. The primary endpoint was the composite of aortic valve reintervention and death. Results: The metaanalysis included 4145 patients: 2101 underwent TAVR (mean age $81.7 \pm 6.7$ years, $54 \%$ male) and 2044 SAVR (mean age $81.8 \pm 6.6$ years, $54 \%$ male). All TAVR procedures were performed with early generations of THV. At a median follow-up of 5 years (range 5 - 6 years), TAVR had higher reintervention rates (odds ratio (OR) 3.33; 95\% CI: $[1.78,6.24], \mathrm{p}<0.001, \mathrm{I}^{2}=0 \%$ ), all-cause mortality (OR 1.45; 95\% CI: $[1.22,1.75], \mathrm{p}<0.001, \mathrm{I}^{2}=44 \%$ ) and the composite of reintervention and death (OR 1.47; 95\% CI: [1.14, 1.91], $\mathrm{p}<0.001, \mathrm{I}^{2}=$ $64 \%)$. Rates of myocardial infarction, transient ischemic attack, stroke, endocarditis, and the composite of endocarditis and thrombosis were similar between the groups. Conclusion: Despite comparable short and medium-term results, TAVR with early-generation THV has higher rates of reintervention and the composite of reintervention and death. Further studies employing newer definitions of structural valve deterioration and bioprosthetic valve failure are needed to assess whether technological enhancements in THV technology will improve long-term outcomes.
\end{abstract}




\section{Keywords}

TAVR, SAVR, Structural Valve Deterioration, Bioprosthetic Valve Failure, Durability, Meta-Analysis

\section{Introduction}

In patients with severe aortic stenosis and prohibitive or high surgical risk for aortic valve replacement (SAVR), multiple trials have shown that transcatheter aortic valve replacement (TAVR) is non-inferior to SAVR [1] [2]. These trials resulted in Class 1 evidence indication for TAVR in those with prohibitive or high surgical risk [3]. Recently, major randomized controlled trials have shown TAVR non-inferiority in intermediate and low surgical-risk patients [4] [5]. The expanding indications for TAVR to include lower-risk patients with longer life-expectancy highlight the importance of the long-term durability of transcatheter valves (THV).

There is limited evidence evaluating TAVR outcomes at long-term follow-up, despite the short and medium-term non-inferiority. Therefore, we performed a systematic review and meta-analysis of all studies comparing TAVR to SAVR with a minimum of five years of follow-up to determine the comparative rates of reintervention and death.

\section{Patients and Methods}

\subsection{Literature Search}

We performed the study according to the proposal for conducting and reporting meta-analyses of observational studies [6] and Preferred Reporting Items for Systematic Reviews and Meta-Analyses guidelines (PRISMA) [7]. We performed a computerized search through Medline, Embase, and Cochrane databases from January 2000 to November of 2020. The terms "transcatheter aortic valve replacement", "TAVR", "surgical aortic valve replacement" and "SAVR" were used in combination with "reintervention", "durability", "structural valve deterioration", "SVD", "bioprosthetic valve failure" and "BVF". Bibliographies of the retrieved studies were screened for relevant studies. Our search was limited to the English language.

\subsection{Study Selection}

We included randomized controlled trials (RCTs) and propensity-matched observational studies that compared outcomes with TAVR versus SAVR with clinical follow-up of at least five years. We excluded all non-randomized and singlearm studies, as well as those including only TAVR patients. Due to the exclusion of all studies with $\leq 5$ years of follow-up, only TAVR with early-generation THVs were included (Corevalve, SAPIEN, and SAPIEN XT). Data from the Placement 
of Aortic Transcatheter Valves (PARTNER) 1B trial [8] was not included, as it did not report reintervention. Of the two publications reporting the results of the Nordic Aortic Valve Intervention (NOTION) trial at $\geq 5$ years of follow-up, only the one with data on reintervention, death, and major adverse cardiovascular events (MACE) was included [9]. Similarly, we utilized the PARTNER 2A trial comparing SAPIEN XT and SAVR for clinical outcomes [10], excluding the propensity-matched analysis which included the non-randomized SAPIEN-3 registry [11]. Though five of the studies reported structural valve deterioration (SVD) or bioprosthetic valve failure (BVF), this data was excluded from our analysis due to: 1) use of standardized definitions in only four of the studies; 2) the dissimilarity in definitions; 3 ) definitions that were set after trials and not a priori; and 4) the lack of independent SVD and BVF adjudication.

\subsection{Data Extraction and Quality Assessment}

The data were reviewed and extracted by two independent investigators (KB, $\mathrm{MM}$ ). Discrepancies were settled by consensus. The bias risk of the included studies was assessed using the New-Castle Ottawa Scale for cohort studies and the Cochrane risk assessment tool for RCTs [12].

\subsection{Data Synthesis and Statistical Analysis}

Statistical analysis was conducted using Review Manager Software (Version 5.4.1. Copenhagen: The Nordic Cochrane Centre, the Cochrane Collaboration, 2014). Categorical variables were reported as frequencies, while continuous variables as means with standard deviations (SD). Categorical variables were compared using Fisher's exact or Chi-square tests, while continuous variables were analyzed using the two-sample t-test. Tests were two-tailed, and a p-value of $\leq$ 0.05 was considered statistically significant. All reported baseline characteristics and outcomes are weighted by sample size.

Odds ratios (ORs) and mean differences (MD) with 95\% confidence intervals (CIs) are presented as summary statistics. Statistical heterogeneity was assessed by $\mathrm{I}^{2}$ statistics: $\mathrm{I}^{2}$ statistic $>50 \%$ was considered substantial, and $\mathrm{I}^{2}>75 \%$ was considered considerable [13]. We used the Der-Simonian and Laird random-effects and random-effects generic inverse variance methods to calculate $\mathrm{OR}$ and MD, respectively, as we anticipated a high degree of clinical and methodological heterogeneity. Potential publication bias was assessed using the Egger test by visual examination of the funnel plots [14].

\section{Results}

\subsection{Study Selection and Study Criteria}

The study selection process is described in Supplemental Figure S1. We analysed a total of 4 RCTs and one propensity-matched observational trial, including 2101 TAVR patients and 2044 SAVR patients. TAVR valves deployed included Corevalve $(n=566)$, SAPIEN $(n=425)$, and SAPIEN XT $(n=1105)$ 
(Table 1). All studies included patients with severe aortic stenosis. The average operative risk was considered high in two studies [15] [16] and intermediate to low in three studies [9] [10] [17]. The surgical risk was defined by the STS score. Supplemental Table S1 has a complete list of study inclusion criteria and definitions. Bias assessment was determined using the New-Castle Ottawa Scale for observational studies and the Cochrane assessment tool for RCTs (Supplemental Table S2 and Table S3).

Table 1. Characteristics of the included studies.

\begin{tabular}{|c|c|c|c|c|c|c|c|c|}
\hline Study & Trial/Registry & Study Type & $\begin{array}{c}\text { Number of } \\
\text { patients with } \\
\text { TAVR/SAVR }\end{array}$ & $\begin{array}{c}\text { TAVR } \\
\text { Valve Type }\end{array}$ & $\begin{array}{c}\text { Country } \\
\text { (\# of centers) }\end{array}$ & $\begin{array}{l}\text { Follow-up } \\
\text { time (years) }\end{array}$ & Time Frame & Surgical Risk \\
\hline $\begin{array}{l}\text { Makkar } \\
\text { et al. } 2020\end{array}$ & PARTNER-2 & RCT & $1011 / 1021$ & $\begin{array}{c}\text { TAVR: } \\
\text { 100\% Sapien XT } \\
\text { SAVR: Not } \\
\text { discussed }\end{array}$ & $\begin{array}{c}\text { US and } \\
\text { Canada (57) }\end{array}$ & 5 & $\begin{array}{l}\text { December } 2011 \\
\text { - } \\
\text { November } 2013\end{array}$ & Intermediate \\
\hline $\begin{array}{l}\text { Tzamalis } \\
\text { et al. } 2020\end{array}$ & $\begin{array}{l}\text { Karlsruhe } \\
\text { Registry }\end{array}$ & $\begin{array}{l}\text { Observational } \\
\text { (propensity } \\
\text { matched) }\end{array}$ & $216 / 216$ & $\begin{array}{c}\text { 37.5\% Sapien } \\
\text { 43.5\% Sapien XT } \\
\text { 16.7\% CoreValve } \\
\text { 1.4\% Symetic } \\
\text { Accurate } \\
\text { 1.3\% Jenna Valve } \\
\text { SAVR: } \\
\text { 34.3\% Hancock, } \\
\text { 22.7\% SJM, } \\
\text { 0.5\% Mitroflow, } \\
\text { 1.9\% ATS, } \\
\text { 40.7\% Perimount }\end{array}$ & Germany (1) & 6 & $\begin{array}{l}\text { April } 2008 \\
\quad- \\
\text { April } 2012\end{array}$ & $\begin{array}{l}\text { Intermediate } \\
\text { and low risk }\end{array}$ \\
\hline $\begin{array}{l}\text { Sondergaard } \\
\text { et al } 2019\end{array}$ & NOTION & $\begin{array}{c}\text { RCT, } \\
\text { unblinded }\end{array}$ & $139 / 135$ & $\begin{array}{l}\text { TAVR: } 100 \% \\
\text { first-generation } \\
\text { CoreValve } \\
\text { SAVR: Any } \\
\text { bioprosthetic } \\
\text { aortic valve } \\
\text { (27\% Mosaic, } \\
29 \% \text { Epic, } \\
24 \% \text { Trifecta, } \\
10 \% \text { Perimount, } \\
\text { and 10\% } \\
\text { Sorin Mitroflow) }\end{array}$ & $\begin{array}{l}\text { Denmark, } \\
\text { Sweden (3) }\end{array}$ & 6 & $\begin{array}{c}\text { December } 2009 \\
- \\
\text { April } 2013\end{array}$ & $\begin{array}{l}\text { All-comers } \\
\text { mostly at } \\
\text { lower risk }\end{array}$ \\
\hline $\begin{array}{l}\text { Gleason } \\
\text { et al. } 2018\end{array}$ & $\begin{array}{c}\text { CoreValve } \\
\text { U.S. Pivotal } \\
\text { High-Risk } \\
\text { Trial }\end{array}$ & RCT & $391 / 359$ & $\begin{array}{l}\text { TAVR: } 100 \% \\
\text { Core Valve } \\
\text { SAVR: } \\
\text { biological valve } \\
(98.6 \%), \\
\text { mechanical valve } \\
(1.4 \%) .\end{array}$ & USA (45) & 5 & $\begin{array}{c}\text { February } 2011 \\
- \\
\text { September } 2012\end{array}$ & High \\
\hline $\begin{array}{c}\text { Mack } \\
\text { et al. } 2015\end{array}$ & PARTNER-1A & RCT & $348 / 351$ & $\begin{array}{c}\text { 100\% Sapien } \\
\text { SAVR: not } \\
\text { discussed }\end{array}$ & $\begin{array}{l}\text { Canada (2) } \\
\text { Germany (1) } \\
\text { USA (22) }\end{array}$ & 5 & $\begin{array}{c}\text { May } 2007 \\
- \\
\text { August } 2009\end{array}$ & High \\
\hline
\end{tabular}

TAVR: transcatheter aortic valve replacement; SAVR: surgical aortic valve replacement. 


\subsection{Patient Characteristics}

The TAVR group included 2101 patients (mean age $81.7 \pm 6.7$ years, $54 \%$ male) and the SAVR group included 2044 patients (mean age $81.8 \pm 6.6$ years, 54\% male). The median follow-up duration was 5 years (range 5 - 6 years) for clinical outcomes. There were a higher percentage of patients with atrial fibrillation in the SAVR group, though the numeric difference was small. There were no other differences in baseline characteristics between the groups (Table 2).

\subsection{Major Adverse Cardiovascular Events}

During a median follow-up time of 5 years (range 5 - 6 years), TAVR patients had a significantly higher rate of aortic valve reintervention (odds ratio (OR) 3.33; 95\% CI: $\left.[1.78,6.24], \mathrm{p}<0.001, \mathrm{I}^{2}=0 \%\right)$ and the composite of reintervention and death (OR 1.58; 95\% CI: $\left.[1.23,2.02], \mathrm{p}<0.001, \mathrm{I}^{2}=61 \%\right)$ than SAVR patients (Figure 1). TAVR also had higher all-cause mortality (OR 1.46, $\mathrm{p}=$ 0.001 ), the composite of death or repeat hospitalization (OR 1.51, p $<0.001$ ), and trended towards higher cardiac mortality. Rates of myocardial infarction, transient ischemic attack, stroke, endocarditis, and the composite of endocarditis and thrombosis were similar between the TAVR and SAVR groups (Figure 2). Summary statistics are listed in Table 3.

Table 2. Baseline characteristics as reported by individual studies.

\begin{tabular}{cccc}
\hline & TAVR & SAVR & p-value \\
& N $=2101$ & N $=2044$ & \\
\hline Age mean \pm SD & $81.7 \pm 6.7$ & $81.8 \pm 6.6$ & 0.63 \\
Male \% & 53.6 & 54.3 & 0.67 \\
NYHA III or IV \% & $79.8[1889]$ & $79.4[1866]$ & 0.79 \\
Diabetes \% & $35.1[1541]$ & $35.6[1515]$ & 0.80 \\
Creatinine > 2 mg/dL & 5.2 & 4.8 & 0.60 \\
Peripheral vascular disease & 29.0 & 31.5 & 0.09 \\
Cerebrovascular disease & $30.0[1750]$ & $29.0[1731]$ & 0.54 \\
COPD/Chronic lung disease & $35.2[1889]$ & $34.0[1866]$ & 0.46 \\
Permanent pacemaker & $15.0[1889]$ & $15.1[1866]$ & 0.97 \\
Atrial fibrillation/flutter & $34.7[1889]$ & $38.1[1866]$ & 0.03 \\
Coronary artery disease & $67.9[1618]$ & $66.1[1596]$ & 0.29 \\
Prior CABG & $28.7[1750]$ & $30.5[1731]$ & 0.26 \\
STS Score mean \pm SD & $7.0 \pm 3.6[1889]$ & $7.0 \pm 3.6[1886]$ & $>0.99$ \\
LVEF (\%) & $57.1 \pm 11.5[1618]$ & $56.3 \pm 12.0[1596]$ & 0.05 \\
\hline
\end{tabular}

CABG: coronary artery bypass graft; COPD: chronic obstructive pulmonary disease; LVEF: left ventricular ejection fraction; NYHA: New York Heart Association; STS: Society for Thoracic Surgeons. Numbers between square brackets represent the number of subjects with a reported variable when different from baseline. 


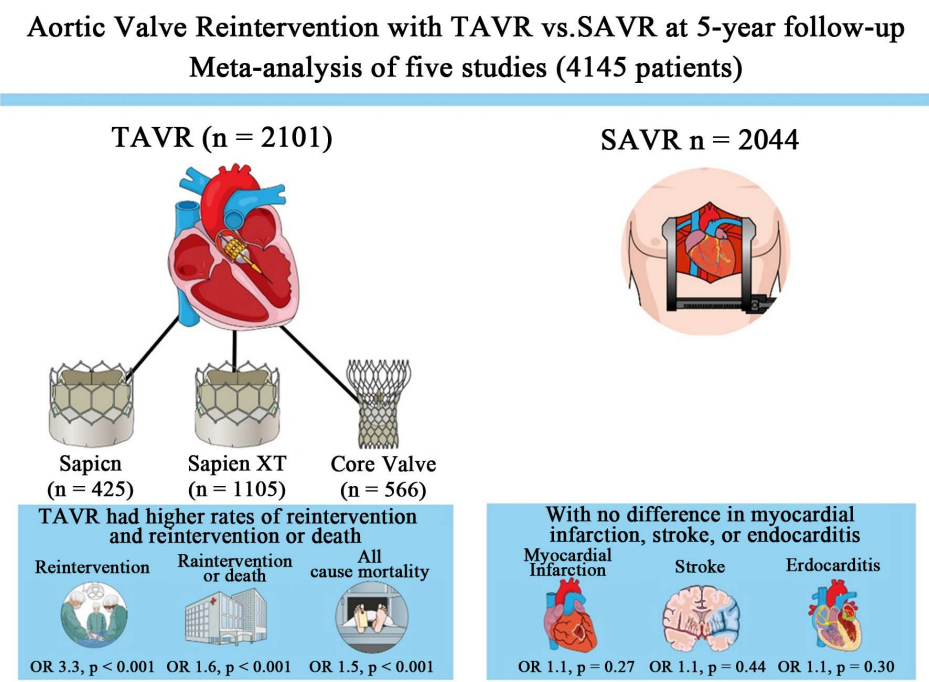

Figure 1. Incidence of aortic valve reintervention, death, all-cause mortality, and major adverse cardiovascular and cerebrovascular events at $\geq 5$ years of follow-up.

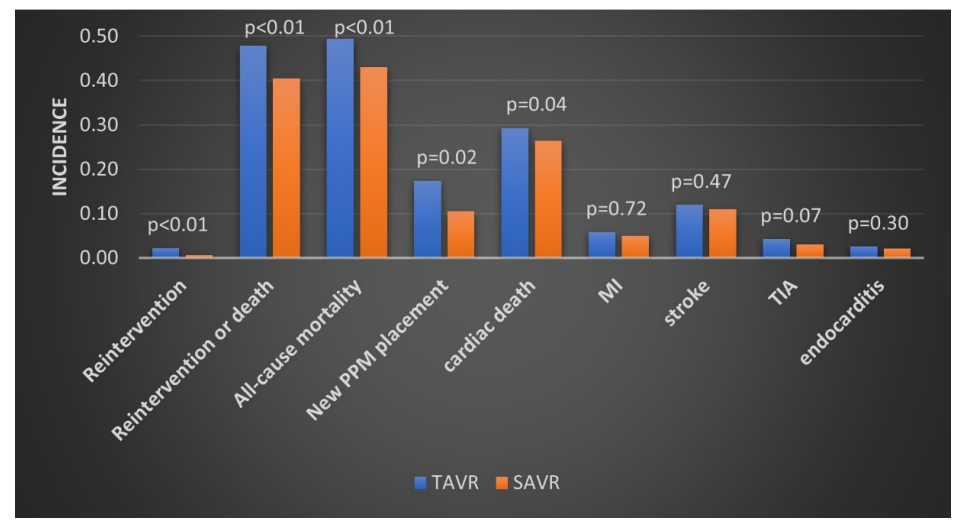

Figure 2. incidence of adverse events with TAVR vs. SAVR at maximum follow-up.

Table 3. Effect of TAVR vs. SAVR on adverse events and valve deterioration.

\begin{tabular}{ccccc}
\hline & Odds Ratio & 95\% CI & p value & $\mathrm{I}^{2}(\%)$ \\
\hline Adverse Events & 1.45 & $1.22,1.75$ & $<0.001$ & 44 \\
All-cause mortality & 1.16 & $1.00,1.34$ & $\mathbf{0 . 0 4}$ & 0 \\
Cardiac mortality & 1.37 & $0.97,1.94$ & 0.07 & 0 \\
TIA & 1.08 & $0.89,1.31$ & 0.44 & 0 \\
Stroke & 1.19 & $0.87,1.61$ & 0.27 & 7 \\
Myocardial Infarction & 1.51 & $1.31,1.73$ & $<0.001$ & 0 \\
Repeat hospitalization or death & 3.33 & $1.78,6.24$ & $<0.001$ & 0 \\
Reintervention & 1.58 & $1.23,2.02$ & $<0.001$ & 61 \\
Reintervention or death & 1.26 & $0.81,1.94$ & 0.30 & 0 \\
Endocarditis & 1.01 & $0.50,2.02$ & 0.98 & 0 \\
\hline
\end{tabular}

TIA: transient ischemic attack. 


\section{Discussion}

Our main findings can be summarized as follows: 1) TAVR with first and second-generation THV devices was associated with higher rates of reintervention, the composite of reintervention and death, and all-cause mortality relative to SAVR at $\geq 5$ years of follow-up; 2) rates of myocardial infarction, transient ischemic attack, and stroke were similar; and 3) there was no difference in the incidence of endocarditis or the composite of endocarditis and thrombosis.

TAVR has many advantages, the most obvious of which is its availability in patients with prohibitively high surgical risk. Similarly, there is mounting evidence on the benefits of TAVR across the spectrum of surgical risks. As a result of the expanding indications for TAVR to include lower-risk patients with longer life expectancy, the long-term durability of transcatheter valves is becoming increasingly important. In our study, patients who underwent TAVR with earlygeneration THV devices had a higher rate of the composite of death or reintervention and all-cause mortality.

Recent data suggest that TAVR durability depends heavily on valve-subtype. The propensity-matched analysis by Pibarot et al. compared the outcomes of the third generation SAPIEN 3 and the second generation SAPIEN XT THV and found a lower rate of SVD and BVF in the SAPIEN 3 cohort [11]. Similarly, The Comparison of Transcatheter Heart Valves in High Risk Patients with Severe Aortic Stenosis (CHOICE) trial compared the Edwards SAPIEN XT with the Medtronic CoreValve and found a higher rate of SVD in the SAPIEN XT patients.

Aortic valve reintervention, albeit clinically important, lacks sensitivity and specificity to detect structural valve deterioration. For example, a patient with severe perivalvular regurgitation, which was more common with first and secondgeneration THV devices, might have required reintervention unrelated to structural valve degeneration. Conversely, a patient with significant structural valve deterioration might have been denied surgery due to prohibitive surgical risk. Recognizing these limitations, standardized definitions of structural valve deterioration and bioprosthetic valve failure have been proposed by the Valve Academic Research Consortium (VARC-3). SVD is defined as a composite of $\geq$ Stage 2 hemodynamic valve deterioration by echocardiography and/or SVD-related bioprosthetic valve failure (BVF). BVF is defined as: 1) symptomatic bioprosthetic valve dysfunction or severe Stage 3 hemodynamic valve deterioration; 2) valve reintervention; or 3) valve-related death (Supplemental Table S4 and Table S5). Recently, the European Association of Percutaneous Cardiovascular Interventions (EAPCI), the European Society of Cardiology (ESC), and the European Association for Cardio-Thoracic Surgery (EACTS) also proposed standardized definitions of structural valve dysfunction, including SVD, non-structural valve deterioration, and BVF [18].

\section{Limitations}

Our study has several limitations. First, it has limited power to detect differences 
in clinical outcomes due to the small number of studies $(n=5)$, the inclusion of observational studies $(n=1)$, and events with a significant degree of heterogeneity. We attempted to overcome this limitation by excluding non-propensity-matched and non-randomized studies and by using a random-effects model in our analysis. Second, it is unknown to what degree the need for permanent pacemaker placement (higher following TAVR) affected our outcomes. Third, valve type and surgical risk were likely significant confounding factors. There is evidence that technological (outer skirts) and procedural enhancements (sizing with CT) have improved outcomes with newer generation THV [11]. Fourth, the THVs included in this meta-analysis are no longer commercially available in the US.

\section{Conclusion}

During long-term follow-up, TAVR with early-generation THV devices has higher rates of reintervention and the composite of reintervention and death compared with SAVR, despite comparable short and medium-term results. Further studies employing newer definitions of SVD are needed to assess whether improvements in THV technology will improve long-term outcomes.

\section{Acknowledgements}

Figure 1 was created in Mind the Graph platform, https://www.mindthegraph.com.

\section{Conflicts of Interest}

The authors declare no conflicts of interest regarding the publication of this paper.

\section{References}

[1] Leon, M.B., Smith, C.R., Mack, M., et al. (2010) Transcatheter Aortic-Valve Implantation for Aortic Stenosis in Patients Who Cannot Undergo Surgery. The New England Journal of Medicine, 363, 1597-1607. https://doi.org/10.1056/NEJMoa1008232

[2] Popma, J.J., Adams, D.H., Reardon, M.J., et al. (2014) Transcatheter Aortic Valve replacement Using a Self-Expanding Bioprosthesis in Patients with Severe Aortic Stenosis at Extreme Risk for Surgery. Journal of the American College of Cardiology, 63, 1972-1981. https://doi.org/10.1016/j.jacc.2014.02.556

[3] Nishimura, R.A., Otto, C.M., Bonow, R.O., et al. (2017) 2017 AHA/ACC Focused Update of the 2014 AHA/ACC Guideline for the Management of Patients With Valvular Heart Disease: A Report of the American College of Cardiology/American Heart Association Task Force on Clinical Practice Guidelines. Journal of the American College of Cardiology, 70, 252-289. https://doi.org/10.1016/j.jacc.2017.03.011

[4] Leon, M.B., Smith, C.R., Mack, M.J., et al. (2016) Transcatheter or Surgical Aortic-Valve Replacement in Intermediate-Risk Patients. The New England Journal of Medicine, 374, 1609-1620. https://doi.org/10.1056/NEJMoa1514616

[5] Mack, M.J., Leon, M.B., Thourani, V.H., et al. (2019) Transcatheter Aortic-Valve Replacement with a Balloon-Expandable Valve in Low-Risk Patients. The New England Journal of Medicine, 380, 1695-1705. 
https://doi.org/10.1056/NEJMoa1814052

[6] Stroup, D.F., Berlin, J.A., Morton, S.C., et al. (2000) Meta-Analysis of Observational Studies in Epidemiology: A Proposal for Reporting. JAMA, 283, 2008.

https://doi.org/10.1001/jama.283.15.2008

[7] Moher, D., Liberati, A., Tetzlaff, J., Altman, D.G. and Group, T.P. (2009) Preferred Reporting Items for Systematic Reviews and Meta-Analyses: The PRISMA Statement. PLoS Medicine, 6, e1000097. https://doi.org/10.1371/journal.pmed.1000097

[8] Kapadia, S.R., Leon, M.B., Makkar, R.R., et al. (2015) 5-Year Outcomes of Transcatheter Aortic Valve Replacement Compared with Standard Treatment for Patients with Inoperable Aortic Stenosis (PARTNER 1): A Randomised Controlled Trial. Lancet, 385, 2485-2491. https://doi.org/10.1016/S0140-6736(15)60290-2

[9] Søndergaard, L., Ihlemann, N., Capodanno, D., et al. (2019) Durability of Transcatheter and Surgical Bioprosthetic Aortic Valves in Patients at Lower Surgical Risk. Journal of the American College of Cardiology, 73, 546-553.

https://doi.org/10.1016/j.jacc.2018.10.083

[10] Makkar, R.R., Thourani, V.H., Mack, M.J., et al. (2020) Five-Year Outcomes of Transcatheter or Surgical Aortic-Valve Replacement. The New England Journal of Medicine, 382, 799-809. https://doi.org/10.1056/NEJMoa1910555

[11] Pibarot, P., Ternacle, J., Jaber, W.A., et al. (2020) Structural Deterioration of Transcatheter Versus Surgical Aortic Valve Bioprostheses in the PARTNER-2 Trial. Journal of the American College of Cardiology, 76, 1830-1843. https://doi.org/10.1016/j.jacc.2020.08.049

[12] Wells, G, Shea, B, O'Connell, D, et al. (2011) The Newcastle-Ottawa Scale (NOS) for Assessing the Quality of Nonrandomised Studies in Meta-Analyses. http://www.ohri.ca/programs/clinical_epidemiology/oxford.asp

[13] Higgins, J.P.T., Thompson, S.G., Deeks, J.J. and Altman, D.G. (2003) Measuring inconsistency in meta-analyses. BMJ, 327, 557-560.

https://doi.org/10.1136/bmj.327.7414.557

[14] Egger, M., Davey Smith, G., Schneider, M. and Minder, C. (1997) Bias in MetaAnalysis Detected by a Simple, Graphical Test. BMJ, 315, 629-634. https://doi.org/10.1136/bmj.315.7109.629

[15] Mack, M.J., Leon, M.B., Smith, C.R., et al. (2015) 5-Year Outcomes of Transcatheter Aortic Valve Replacement or Surgical Aortic Valve Replacement for High Surgical Risk Patients with Aortic Stenosis (PARTNER 1): A Randomised Controlled Trial. Lancet, 385, 2477-2484. https://doi.org/10.1016/S0140-6736(15)60308-7

[16] Gleason, T.G., Reardon, M.J., Popma, J.J., et al. (2018) 5-Year Outcomes of SelfExpanding Transcatheter Versus Surgical Aortic Valve Replacement in High-Risk Patients. Journal of the American College of Cardiology, 72, 2687-2696. https://doi.org/10.1016/j.jacc.2018.08.2146

[17] Tzamalis, P., Alataki, S., Bramlage, P., Schmitt, C. and Schymik, G. (2020) Comparison of Valve Durability and Outcomes of Transcatheter Aortic Valve Implantation Versus Surgical Aortic Valve Replacement in Patients With Severe Symptomatic Aortic Stenosis and Less-Than-High-Risk for Surgery. American Journal of Cardiology, 125, 1202-1208. https://doi.org/10.1016/j.amjcard.2020.01.015

[18] Capodanno, D., Petronio, A.S., Prendergast, B., et al. (2017) Standardized Definitions of Structural Deterioration and Valve Failure in Assessing Long-Term Durability of Transcatheter and Surgical Aortic Bioprosthetic Valves: A Consensus Statement from the European Association of Percutaneous Cardiovascular Interven. European Journal of Cardio-Thoracic Surgery, 52, 408-417. https://doi.org/10.1093/ejcts/ezx244 


\section{Supplemental}

Table S1. Definitions of outcomes, inclusion and exclusion criteria by the included studies.

\begin{tabular}{|c|c|c|c|c|c|c|}
\hline Study & SVD & NSVD & BVF & Endocarditis & Inclusion & Exclusion \\
\hline $\begin{array}{l}\text { Makkar } \\
\text { et al. } 2020\end{array}$ & $\begin{array}{l}\text { Any change in valve } \\
\text { function (a decrease } \\
\text { of one NYHA } \\
\text { functional class } \\
\text { or more) resulting } \\
\text { from an intrinsic } \\
\text { abnormality of the } \\
\text { valve that causes } \\
\text { stenosis or } \\
\text { regurgitation }\end{array}$ & Not Defined & Not Defined & $\begin{array}{l}\text { Abscess, } \\
\text { paravalvular } \\
\text { leak, pus, or } \\
\text { vegetation } \\
\text { confirmed } \\
\text { during a } \\
\text { re-operation } \\
\text { or autopsy }\end{array}$ & $\begin{array}{l}\text { Severe AS, } \\
\text { NYHA class II } \\
\text { or greater, } \\
\text { intermediate } \\
\text { surgical risk }\end{array}$ & $\begin{array}{l}\text { Inoperability, acute MI } \\
\text { within } 30 \text { days, bicuspid } \\
\text { aortic valve, } \mathrm{LVEF}<20 \% \text {, } \\
\text { severe renal insufficiency, } \\
\text { life expectancy }<2 \text { years }\end{array}$ \\
\hline $\begin{array}{l}\text { Tzamalis } \\
\text { et al. } 2020\end{array}$ & $\begin{array}{l}\text { EAPCI/ESC/EACTS } \\
\text { definitions }\end{array}$ & $\begin{array}{l}\text { EAPCI/ESC/EACTS } \\
\text { definitions }\end{array}$ & $\begin{array}{l}\text { EAPCI/ESC/EACTS } \\
\text { definitions }\end{array}$ & Not defined & $\begin{array}{l}\text { Severe AS } \\
\text { with } \\
\text { intermediate } \\
\text { or low } \\
\text { surgical risk }\end{array}$ & $\begin{array}{l}\text { Surgical patients who } \\
\text { required concomitant } \\
\text { mitral repair, mitral } \\
\text { replacement, or CABG }\end{array}$ \\
\hline $\begin{array}{l}\text { Sondergaard } \\
\text { et al } 2019\end{array}$ & $\begin{array}{l}\text { EAPCI/ESC/EACTS } \\
\text { definitions }\end{array}$ & $\begin{array}{l}\text { EAPCI/ESC/EACTS } \\
\text { definitions }\end{array}$ & $\begin{array}{l}\text { EAPCI/ESC/EACTS } \\
\text { definitions }\end{array}$ & $\begin{array}{l}\text { Modified } \\
\text { Duke Criteria }\end{array}$ & $\begin{array}{l}\geq 70 \text { years of } \\
\text { age with } \\
\text { severe AS, } \\
\text { NYHA class II } \\
\text { or greater, } \\
\text { regardless } \\
\text { with low } \\
\text { surgical risk }\end{array}$ & $\begin{array}{l}\text { another severe heart } \\
\text { valve disease or CAD } \\
\text { requiring intervention, } \\
\text { previous cardiac surgery, } \\
\text { MI or stroke within } \\
30 \text { days, severe renal } \\
\text { failure requiring dialysis, } \\
\text { or pulmonary failure }\end{array}$ \\
\hline $\begin{array}{l}\text { Gleason } \\
\text { et al. } 2018\end{array}$ & $\begin{array}{l}\text { EAPCI/ESC/EACTS } \\
\text { definitions }\end{array}$ & $\begin{array}{l}\text { EAPCI/ESC/EACTS } \\
\text { definitions }\end{array}$ & $\begin{array}{l}\text { EAPCI/ESC/EACTS } \\
\text { definitions }\end{array}$ & Not defined & $\begin{array}{l}\text { Severe AS, } \\
\text { NYHA } \\
\text { class II or } \\
\text { greater at } \\
\text { high surgical } \\
\text { risk }\end{array}$ & $\begin{array}{l}\text { Recent MI within } \\
30 \text { days, CVA within } \\
6 \text { months, live } \\
\text { expectancy }<12 \text { months }\end{array}$ \\
\hline $\begin{array}{c}\text { Mack } \\
\text { et al. } 2015\end{array}$ & Not defined & Not defined & Not defined & Not defined & $\begin{array}{l}\text { Severe AS } \\
\text { with high } \\
\text { surgical risk }\end{array}$ & $\begin{array}{l}\text { Bicuspid aortic valve, } \\
\text { CAD requiring } \\
\text { revascularization, } \\
\text { LVEF }<20 \% \text {, severe } \\
\text { MR or AR, severe renal } \\
\text { insufficiency, or a recent } \\
\text { neurologic event. }\end{array}$ \\
\hline
\end{tabular}

AR: aortic regurgitation; AS: aortic stenosis; BVF: bioprosthetic valve failure; CAD: coronary artery disease; CVA: cerebrovascular accident; EACTS: European Association of Cardio-Thoracic Surgery; EAPCI: European Association of Percutaneous Cardiovascular Interventions; ESC: European Society of Cardiology; MR: mitral regurgitation; NSVD: non-structural valve deterioration; NYHA: New York Heart Association; VARC: Valve Academic Research Consortium-2; SAVR: surgical aortic valve replacement; SVD: structural valve deterioration.

Table S2. Bias risk assessment of observational studies using the New-Castle-Ottawa scale.

\begin{tabular}{|c|c|c|c|c|c|c|c|c|c|c|}
\hline Study & Year & $\begin{array}{c}\text { Representativeness } \\
\text { of the exposed } \\
\text { cohort }\end{array}$ & $\begin{array}{c}\text { Selection } \\
\text { of the } \\
\text { non-exposed } \\
\text { cohort }\end{array}$ & $\begin{array}{l}\text { Ascertainment } \\
\text { of exposure }\end{array}$ & $\begin{array}{l}\text { Demonstration } \\
\text { of the absence } \\
\text { of outcome } \\
\text { of interest } \\
\text { at the start } \\
\text { of the study }\end{array}$ & $\begin{array}{l}\text { Comparability } \\
\text { (control for } \\
\text { important } \\
\text { factors) } \\
\text { (maximum } \\
\text { two stars) }\end{array}$ & $\begin{array}{l}\text { Assessment } \\
\text { of outcome }\end{array}$ & $\begin{array}{l}\text { Follow-up } \\
\text { adequate } \\
\text { for } \\
\text { outcomes }\end{array}$ & $\begin{array}{l}\text { Adequacy } \\
\text { of follow up }\end{array}$ & $\begin{array}{l}\text { Total } \\
\text { score }\end{array}$ \\
\hline $\begin{array}{l}\text { Tzamalis } \\
\text { et al. } 2020\end{array}$ & 2020 & * & * & * & * & $* *$ & * & * & * & 9 \\
\hline
\end{tabular}

All studies with 7 stars or higher are considered high-quality studies. 
Table S3. Bias risk assessment of randomized controlled trials with the Cochrane assessment tool.

\begin{tabular}{|c|c|c|c|c|}
\hline & $\begin{array}{c}\text { Mack } \\
\text { et al. } 2015\end{array}$ & $\begin{array}{l}\text { Gleason } \\
\text { et al. } 2018\end{array}$ & $\begin{array}{l}\text { Sondergaard } \\
\text { et al. } 2019\end{array}$ & $\begin{array}{l}\text { Makkar } \\
\text { et al. } 2020\end{array}$ \\
\hline $\begin{array}{l}\text { Random sequence generation } \\
\text { (Selection bias) }\end{array}$ & + & (?) & + & (?) \\
\hline $\begin{array}{l}\text { Allocation concealment } \\
\quad \text { (Selection bias })\end{array}$ & $\oplus$ & + & $\oplus$ & $\oplus$ \\
\hline $\begin{array}{l}\text { Blinding of participants and personnel } \\
\qquad(\text { Performance bias })^{*}\end{array}$ & (?) & (?) & (?) & (?) \\
\hline $\begin{array}{l}\text { Blinding of outcome assessment } \\
\text { (Detection bias) }\end{array}$ & $\oplus$ & + & $\oplus$ & $\oplus$ \\
\hline $\begin{array}{l}\text { Incomplete outcome data } \\
\text { (Attrition bias })\end{array}$ & $\oplus$ & $\oplus$ & + & $\oplus$ \\
\hline $\begin{array}{l}\text { Selective reporting } \\
\quad \text { (Reporting bias) }\end{array}$ & + & (?) & (?) & (?) \\
\hline Other sources of bias & ? & ? & $\oplus$ & $\oplus$ \\
\hline
\end{tabular}

Table S4. Valve Academic Research Consortium (VARC)-3 standardized definitions of bioprosthetic valve dysfunction*.

\section{Categories of Bioprosthetic Valve Dysfunction}

\section{Structural valve deterioration}

- Intrinsic permanent changes to the prosthetic valve, including leaflet tear, disruption, flail leaflet, leaflet fibrosis and/or calcification.

- See Online Table 2 for definitions of stages.

\section{Non-structural valve dysfunction}

- Any abnormality, not intrinsic to the prosthetic valve, resulting in valve dysfunction. Examples include residual intra- or para-prosthetic aortic regurgitation; leaflet entrapment by pannus, tissue, or suture; inappropriate positioning or sizing; dilatation of the aortic root after stentless prostheses or aortic valve sparing operations; prosthesis-patient mismatch; and embolization.

\section{Valve thrombosis}

- Subclinical: Imaging findings of hypo-attenuated (CT) or hypo-echogenic (echocardiography) leaflet thickening and/or reduced leaflet motion with absent of mild hemodynamic changes and no symptoms/sequelae.

- Clinically significant: 1) Clinical sequelae of thrombo-embolic event or of worsening bioprosthetic valve stenosis or regurgitation and hemodynamic valve deterioration Stage 2 or 3 (See Online Table 2). 2) In the absence of clinical sequelae, both hemodynamic valve deterioration Stage 2 or 3 and confirmatory imaging (leaflet thickening and/or reduced leaflet motion).

\section{Valve endocarditis}

- Meeting at least one of the following criteria: (1) Fulfillment of the Duke endocarditis criteria (2) Evidence of abscess, pus, or vegetation confirmed as secondary to infection by histological or microbiological studies during re-operation; (3) Evidence of abscess, pus, or vegetation confirmed on autopsy.

\section{Clinical Presentation}

\section{Subclinical}

- Stage 1: Any bioprosthetic valve dysfunction associated with absent or mild hemodynamic changes, AND absent symptoms or sequelae. Bioprosthetic valve failure

- Stage 1: Any significant bioprosthetic valve dysfunction with clinically expressive criteria (new-onset or worsening symptoms, LV dilation/hypertrophy/dysfunction, or pulmonary hypertension) OR Stage 3 hemodynamic valve deterioration related to permanent changes to the prosthetic valve.

- Stage 2: Aortic valve reoperation or reintervention.

- Stage 3: Valve-related death. ${ }^{\dagger}$

${ }^{*}$ Table adapted with permission from Pibarot et al. ${ }^{\dagger}$ Cardiovascular mortality presumed to be associated with bioprosthetic valve dysfunction. 
Table S5. Valve Academic Research Consortium (VARC)-3 standardized definitions of the stages of structural valve deterioration*.

\section{Stages of Structural Valve Deterioration}

Stage 1: Morphological valve deterioration

- Intrinsic permanent changes to the prosthetic valve, including leaflet tear, disruption, flail leaflet, leaflet fibrosis and/or calcification without significant hemodynamic changes.

Stage 2: Moderate hemodynamic valve deterioration ${ }^{\dagger}$

- Morphological valve deterioration (See Stage 1) AND:

- Increase in mean transvalvular gradient $\geq 10 \mathrm{mmHg}$ resulting in mean gradient $\geq 20 \mathrm{mmHg}^{\ddagger}$ with concomitant decrease in aortic valve area (AVA) $\geq 0.3 \mathrm{~cm}^{2}$ or $\geq 25 \%$ and/or decrease in Doppler velocity index $\geq 0.1$ or $\geq 20 \%$ compared to echocardiographic assessment performed 1 to 3 months post-procedure (or discharge if not available), OR new occurrence or increase of $\geq 1$ grade of transvalvular aortic regurgitation (AR) resulting in moderate transvalvular AR.

Stage 3: Severe hemodynamic valve deterioration ${ }^{\dagger}$

- Morphological valve deterioration (See Stage 1) AND:

- Increase in mean transvalvular gradient $\geq 20 \mathrm{mmHg}$ resulting in mean gradient $\geq 30 \mathrm{mmHg}^{\ddagger}$ with concomitant decrease in AVA $\geq 0.6 \mathrm{~cm}^{2}$ or $\geq 50 \%$ and/or decrease in Doppler velocity index $\geq 0.2$ or $\geq 40 \%$ compared to echocardiographic assessment performed 1 to 3 months

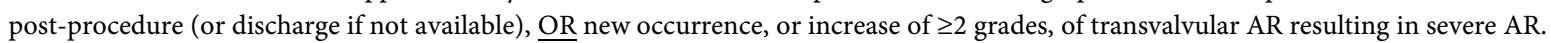

*Table adapted with permission from Pibarot et al. ${ }^{\dagger}$ When assessing the presence and severity of hemodynamic valve deterioration, it is important to differentiate true-hemodynamic changes versus inter-echo variability in. the measurement of gradient, AVA, Doppler velocity index, or AR. In particular, one should use the same window for continuous-wave Doppler interrogation when comparing gradients in early (1 to 3 months) post-procedural echo versus follow-up echo. Each case with potential hemodynamic valve deterioration should be individually adjudicated to confirm presence, stage, and etiology. Hemodynamic valve deterioration may be caused by structural valve deterioration but also by non-structural dysfunction including valve thrombosis and endocarditis. The assessment of valve leaflet morphology and structure is key to make differential diagnosis between the different etiologies of hemodynamic valve deterioration: SVD versus valve thrombosis or endocarditis. ${ }^{*}$ This criteria for hemodynamic dysfunction assume normal flow.

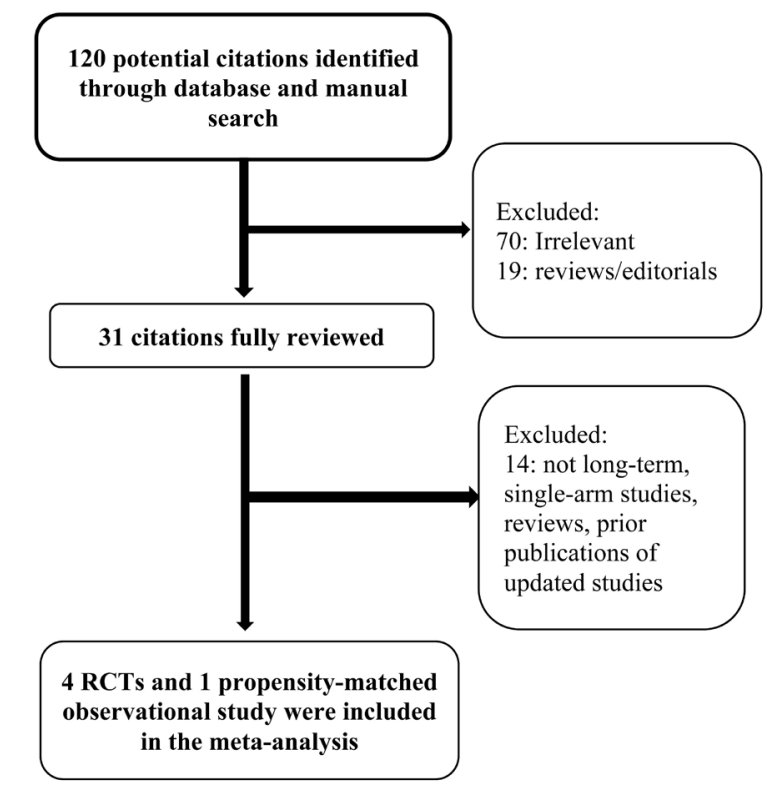

Figure S1. Systematic review process. 